\title{
Chemotherapy Induced Adverse Drug Reactions in Cancer Patients in a Tertiary Care Hospital in South India
}

\author{
Sapan Kumar Behera', Chenchu Reddy Kishtapati², Vikneswaran Gunaseelan', Biswajit Dubashi ${ }^{3}$, Adithan Chandrasekaran ${ }^{4}$, \\ Sandhiya Selvarajan ${ }^{1 *}$ \\ 'Department of Clinical Pharmacology, JIPMER, Puducherry, INDIA. \\ 2Pharmacovigilance Associate, ADR Monitoring Centre, JIPMER, Puducherry, INDIA. \\ ${ }^{3}$ Department of Medical Oncology, JIPMER, Puducherry, INDIA. \\ ${ }^{4}$ Director, Centre for Inter Disciplinary Research, MGMCRI, Puducherry Chairman, IEC, VCRC, INDIA.
}

\section{ABSTRACT}

Objective: To evaluate the pattern of adverse drug reactions (ADRs) reported in cancer patients receiving anticancer drugs in an adverse drug reaction monitoring centre (AMC). Methods: The anticancer drug related ADRs received in $\mathrm{AMC}$ through spontaneous reporting and active surveillance methods from January 2014 to June 2016 were analyzed for demographic profile, organ system and department wise distribution of ADRs, common ADRs encountered, drugs responsible for causing ADRs, ADRs reported by healthcare professionals, number of ADR/ ADRs developed per patient and causality assessment of reported ADRs. Descriptive statistics were used for analysis and the values were expressed in numbers and percentages. Results: 2209 ADRs were reported from 1869 patients comprising of 764 males $(40.88 \%)$ and 1105 females $(59.12 \%)$. In our study, the most common ADRs observed were anemia (12.68\%), neuropathy $(11.18 \%)$ and neutropenia $(6.07 \%)$. Causality assessment of ADRs by WHO-UMC causality scale revealed that $90.9 \%$ of ADRs were possible followed by $4.48 \%$ probable and $2.39 \%$ possible. The most common organ system wise classified ADRs were blood $(24.22 \%)$ related reactions followed by gastrointestinal system $(14.17 \%)$ related adverse effects. The most common drugs associated with ADRs were imatinib (13.94\%) followed by docetaxel $(9.55 \%)$, gemcitabine (8.56\%) and paclitaxel (7.38\%). Amidst 1869 patients,
\end{abstract}

$301(13.63 \%)$ patients had developed two ADRs while 39 (1.76\%) patients experienced three ADRs. Conclusion: The average ADR encountered per patient due to anticancer drug was about 1.18 in this study. Anemia, neuropathy and neutropenia were the most common ADRs reported.

Key words: Anticancer drugs, Chemotherapy, Tertiary care hospital, ADR monitoring centre (AMC).

Key message: Cancer is one of the leading causes of death globally. Owing to narrow therapeutic window, patients taking anticancer drugs have higher risk for developing adverse drug reactions. Hence a study is needed to evaluate the occurrence of adverse drug reactions caused by anticancer drugs.

Correspondence :

Sandhiya Selvarajan, Assistant Professor, Department of Clinical Pharmacology, JIPMER, Puducherry - 605006, INDIA.

Phone: 0413-2296220

Email: sandhiyaselvarajan@gmail.com

DOI: 10.5530/jyp.2017.9.113

\section{INTRODUCTION}

Cancer is one of the leading causes of death in both developed and developing countries. ${ }^{1}$ According to International Agency for Research on Cancer, GLOBOCAN 2012, an estimated 14.1 million new cancer cases and 8.2 million cancer-related deaths occurred in 2012 and new cancer cases may increase to 19.3 million per year by $2025 .^{2}$ Chemotherapy, radiotherapy, surgery, hormonal therapy, immunotherapy, biologic therapy and cryosurgery are the different treatment modalities available for cancer. Chemotherapy, immunotherapy and hormonal therapy are the treatment options in the early stages of cancer. ${ }^{3}$ As anticancer drugs have narrow therapeutic index, adverse drug reactions (ADRs) to these medications are high compared to other classes of drugs. According to WHO, adverse drug reaction (ADR) is defined as "any response to a drug which is noxious and unintended and which occurs at doses normally used in man for prophylaxis, diagnosis, or therapy of disease, or for the modification of physiological function." According to an epidemiological research performed in Australia, antineoplastic and immunosuppressive drugs are associated with $11 \%$ of adverse drug reactions (ADRs) in Australian hospitals with antineoplastic drugs being the most common agents responsible for medication-related hospitalizations. ${ }^{5}$ Similarly a study conducted in South Indian hospital has reported antineoplastic agents as the common class of drugs causing ADRs accounting for a total of $21.8 \%$ of the reported ADRs. ${ }^{6} \mathrm{~A}$ recent study on global patterns of ADRs over a decade has documented that high-income countries have more ADRs from antineoplastic and immune-modulating agents.

In addition to increasing the length of hospital stay, ADRs also significantly increase the health cost. The estimated total cost of treatment for ADRs is $1.7 \%$ of the total hospital budget with a median cost of 8517 francs. ${ }^{8}$ Most of the ADRs with these drugs are unreported due to unawareness of healthcare professionals, lack of time to report and a dearth of sufficient staff in the hospitals. Hence it is necessary to recognize the pattern of ADRs occurring with anticancer drugs so as to enhance the quality of life and to reduce the cost of ADR related hospitalization among cancer patients. Thus the present study is aimed to determine the pattern of adverse drug reactions occurring with anticancer drug in a tertiary care hospital.

\section{MATERIALS AND METHODS}

Adverse drug reactions reported to the ADR monitoring Centre (AMC) functioning in a tertiary care South Indian hospital from January 2014 to June 2016 were collected. Among the ADRs reported to AMC during this period, ADRs related to anticancer drugs were segregated and analyzed. $\mathrm{ADR}$ due to anticancer drugs reported to AMC by both spontaneous

This is an open access article distributed under the terms of the Creative Commons Attribution-NonCommercial-ShareAlike 4.0 License, which allows others to remix, tweak, and build upon the work non-commercially, as long as the author is credited and the new creations are licensed under the identical terms. 
reporting and active surveillance methods were included. Though spontaneous reporting by healthcare professionals is the common method of reporting, active surveillance plays a significant role in detecting newer and rare ADRs within a short period. ${ }^{9}$ Hence, ADRs reported by both the methods were included for analysis. Suspected adverse drug reaction reporting form was used by AMC for reporting of ADRs as a part of the Pharmacovigilance program of India (PvPI). The ADRs were classified as certain, probable, possible, unlikely, unclassified or unclassifiable using WHO-UMC causality assessment scale. ${ }^{4}$ Causality assessment was done by a team of Clinical Pharmacologists and Pharmacovigilance Associate (PA) working under Pharmacovigilance Programmer of India (PvPI). As and when required the opinion of the consultants of concerned departments were taken into consideration for the causality assessment. All the data were presented in percentage.

\section{RESULTS}

A total of 2209 ADRs with cancer chemotherapy were reported from 1869 cancer patients during the study period. Among the ADRs reported $882(39.93 \%)$ were in males and $1327(60.07 \%)$ were in females as shown in Figure 1. Further analysis based on age, revealed more ADRs in the age group of $41-60$ years $(942,59.4 \%)$ compared to $(163,8.7 \%)$ in the age group of $0-18$ years as shown in Figure 2.

\section{Department wise distribution of ADRs}

Most of the ADRs were collected from Regional cancer centre (RCC), JIPMER $(2122,96.06 \%)$ followed by Medicine (29, 1.31\%), Clinical immunology (21, 0.96\%), Nephrology (12, 0.54\%), Pharmacology (11, 0.49\%) and Dermatology $(2,0.09 \%)$ as shown in Table 1.

\section{Organ system wise distribution of ADRs}

The present study showed that in both males and females, the most affected organ system was blood $(553,24.22 \%)$ followed by skin and appendages $(366,16.57 \%)$, gastrointestinal $(313,14.17 \%)$ and neurological disorder $(301,13.63 \%)$. The least common ADRs noticed were congenital, hearing, vestibular and senses, white and red cell disorders shown in Table 2.

\section{Types of adverse drug reactions (ADRs)}

Most common ADRs encountered were anemia $(280,12.68 \%)$ followed by neuropathy $(247,11.18 \%)$, neutropenia $(134,6.07 \%)$, thrombocytopenia $(126,5.7 \%)$, myalgia $(121,5.47)$, hand foot syndrome (HFS) (119, 5.39\%) as shown Table 3.

\section{Causality assessment of ADRs}

According to WHO-UMC causality assessment scale, out of 2209 ADRs, $52(2.36 \%)$ were certain, 2008 (90.9\%) were possible, 99 (4.48\%) were probable, $46(2.08 \%)$ were unlikely and $4(0.18 \%)$ were unclassified as shown in Figure 3.

\section{Reporting of ADRs}

Among the ADRs reported, 985 (44.59\%) were actively collected by pharmacovigilance associate (PA) followed by spontaneous reporting from pharmacists $(655,29.65 \%)$, doctors $(415,18.79 \%)$, nurses (137, 6.20\%) and $\mathrm{PhD}$ scholars $(17,0.77 \%)$ as shown in Figure 4.

\section{Chemotherapeutic agents}

The most common suspected chemotherapeutic agents causing ADRs in our setting was imatinib $(308,14.26 \%)$ followed by docetaxel $(211$, $9.71 \%)$, gemcitabine $(189,7.96 \%)$ and paclitaxel $(163,7.9 \%)$ as shown Table 4.
Table 1: Department wise distribution of ADRs

\begin{tabular}{cccc}
\hline SI. No. & Department & $\begin{array}{c}\text { Number of } \\
\text { ADRs }\end{array}$ & $\begin{array}{c}\text { Percentage } \\
(\%)\end{array}$ \\
\hline 1 & Regional Cancer Centre (RCC) & $\mathbf{2 1 2 2}$ & 96.06 \\
2 & Medicine & $\mathbf{2 9}$ & 1.31 \\
3 & Clinical immunology & $\mathbf{2 1}$ & 0.96 \\
4 & Nephrology & $\mathbf{1 2}$ & 0.54 \\
5 & Pharmacology & $\mathbf{1 1}$ & 0.49 \\
6 & Clinical pharmacology & $\mathbf{3}$ & 0.13 \\
7 & Surgical oncology & $\mathbf{3}$ & 0.13 \\
8 & Endocrinology & $\mathbf{2}$ & 0.09 \\
9 & Dermatology & $\mathbf{2}$ & 0.09 \\
10 & Cardiology & $\mathbf{1}$ & 0.05 \\
11 & Radiology & $\mathbf{1}$ & 0.05 \\
12 & Neurology & $\mathbf{1}$ & 0.05 \\
13 & Orthopedic & $\mathbf{1}$ & 0.05 \\
Total & & $\mathbf{2 2 0 9}$ & 100 \\
\hline
\end{tabular}

Table 2: Organ system wise distribution of ADRs

\begin{tabular}{|c|c|c|c|}
\hline No. & SYSTEM ORGAN CLASS & No. of ADRs & $\begin{array}{l}\text { Percentage } \\
\text { (\%) }\end{array}$ \\
\hline 1 & Blood disorders & 535 & 24.22 \\
\hline 2 & Skin and appendages disorders & 366 & 16.57 \\
\hline 3 & Gastrointestinal disorders & 313 & 14.17 \\
\hline 4 & Neurological disorders & 301 & 13.63 \\
\hline 5 & Musculoskeletal disorders & 166 & 7.51 \\
\hline 6 & Body as a whole- general disorders & 166 & 7.51 \\
\hline 7 & $\begin{array}{c}\text { Vascular, bleeding and clotting } \\
\text { disorders }\end{array}$ & 98 & 4.44 \\
\hline 8 & Respiratory system disorders & 79 & 3.58 \\
\hline 9 & CNS and PNS disorders & 60 & 2.72 \\
\hline 10 & Psychiatric disorders & 37 & 1.67 \\
\hline 11 & Liver and biliary disorders & 17 & 0.77 \\
\hline 12 & Reproductive disorders & 17 & 0.77 \\
\hline 13 & Cardiovascular disorders & 16 & 0.72 \\
\hline 14 & Urinary system disorders & 12 & 0.54 \\
\hline 15 & Metabolic and nutritional disorders & 12 & 0.54 \\
\hline 16 & Immune disorders and infections & 5 & 0.22 \\
\hline 17 & Vision disorders & 3 & 0.14 \\
\hline 18 & Congenital disorders & 1 & 0.05 \\
\hline 19 & $\begin{array}{l}\text { Hearing, vestibular and senses } \\
\text { disorders }\end{array}$ & 1 & 0.05 \\
\hline 20 & White and red cell disorders & 1 & 0.05 \\
\hline 21 & $\begin{array}{l}\text { Information not found in the } \\
\text { register }\end{array}$ & 3 & 0.13 \\
\hline Total & & 2207 & 100 \\
\hline
\end{tabular}




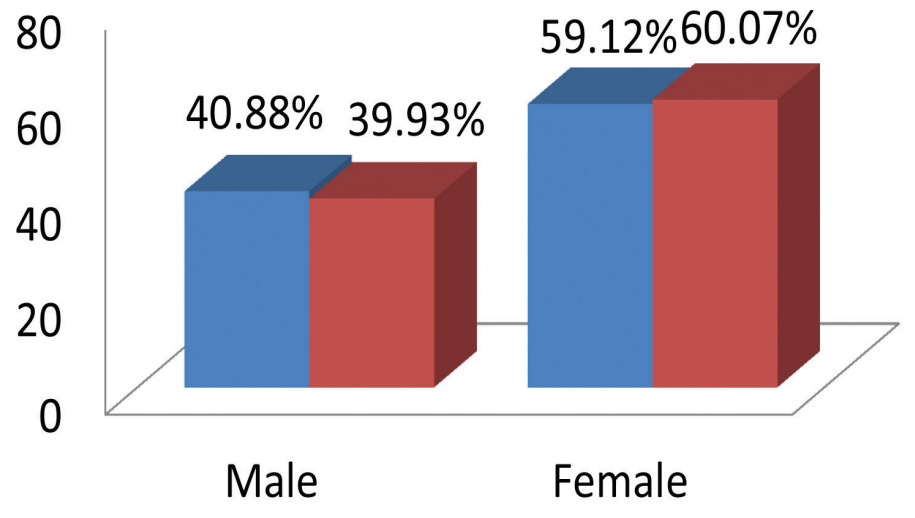

Percentage of patients $\square$ Percentage of ADRs

Figure 1: Gender wise distribution of ADRs

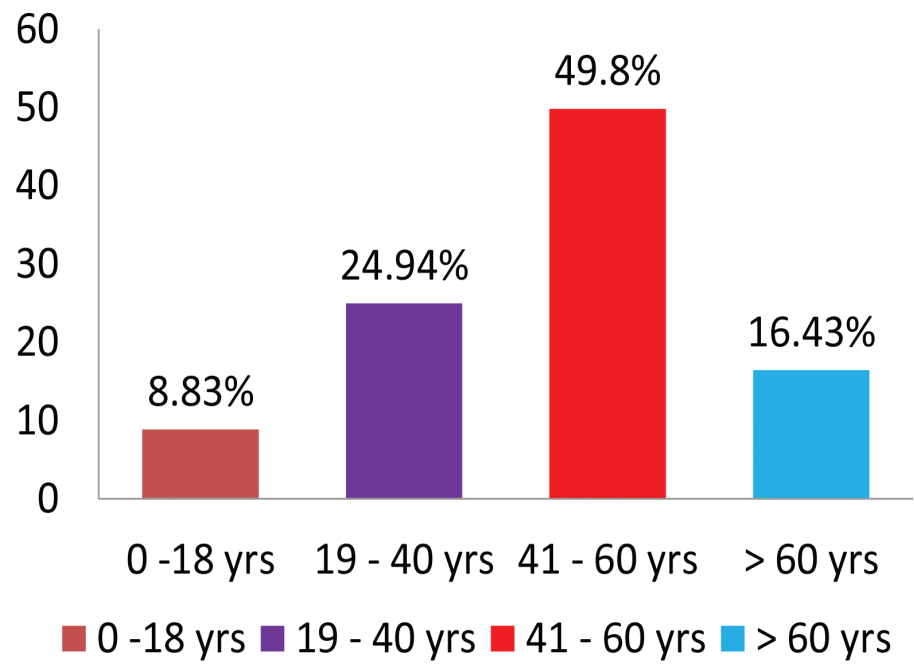

Figure 2: Age wise distribution of ADRs

\section{Number of ADR/ADRs per patient}

A total number of 2209 ADRs were collected from 1869 patients with an average of 1.18 ADRs per patient. 301 (13.63\%) patients experienced two ADRs and 39 (1.77\%) patients developed three ADRs. Thrombocytopenia was the most common $2^{\text {nd }} \mathrm{ADR}$ reported followed by vomiting. Similarly fever and nausea were the most common $3^{\text {rd }}$ ADR observed followed by mucositis. Gemcitabine was the most common drug associated with occurrence of $2^{\text {nd }} A D R$ followed by imatinib. Likewise 5 -fluorouracil was responsible for most common $3^{\text {rd }}$ ADR followed by imatinib and paclitaxel.

\section{DISCUSSION}

The ADRs reported with anticancer drugs for a period of 2.5 years were collected, analyzed and reported from different departments of a multispecialty hospital and research institute in South India. In the present study, ADRs due to anticancer drugs were observed more in females than in male patients. This may be attributed to the smaller body surface area in females. Our finding is similar to the study conducted by Sharma et al. ${ }^{10}$ that showed ADRs in the age group 41-60 years were highest followed by $19-40$ years and lowest in the age group $0-18$ years. This finding

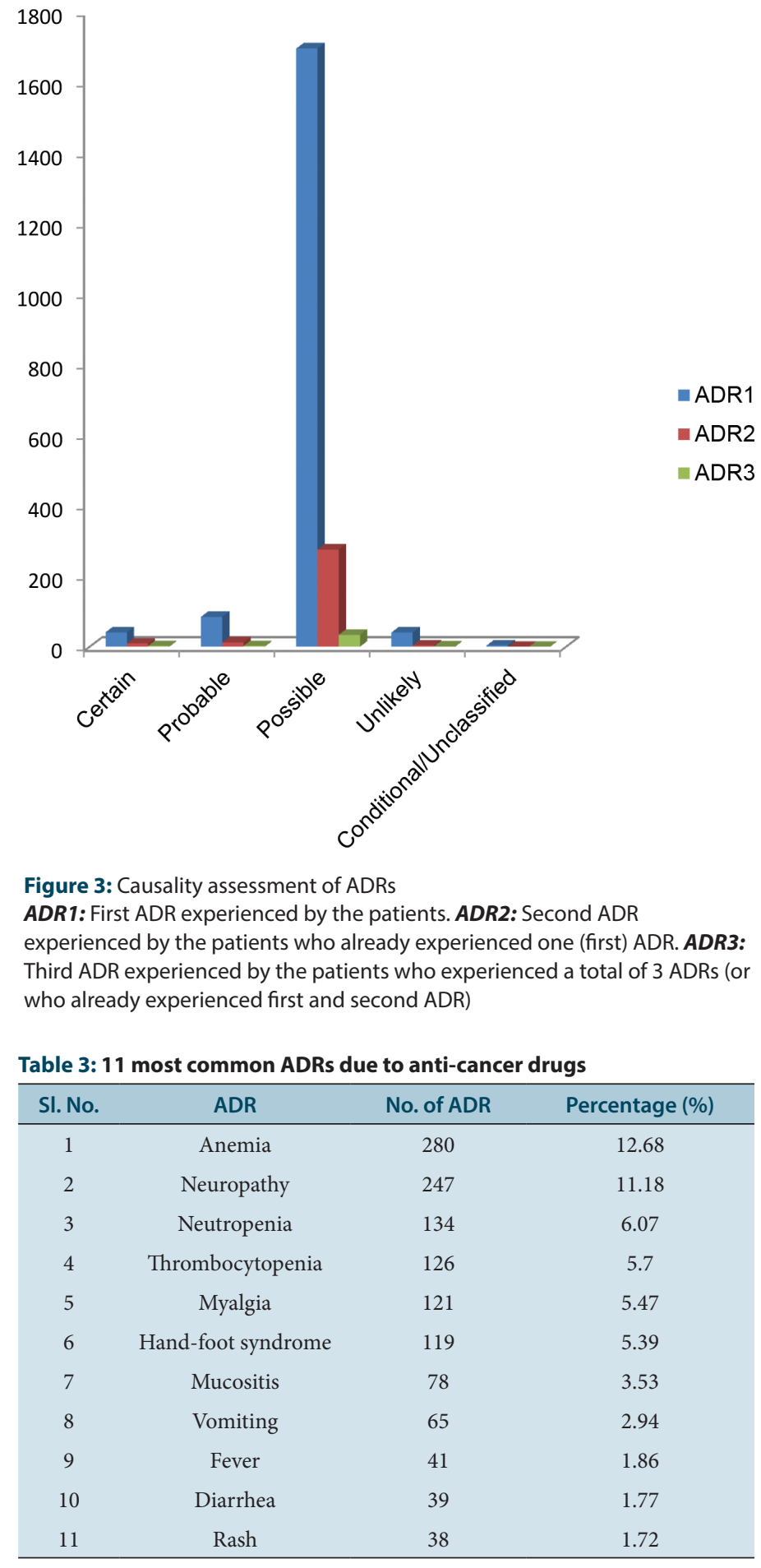

is similar to the report of Pai et al. ${ }^{11}$ who also reported mean age of patients 55.98 years and 52.96 years in male and female respectively. This could be due to the higher incidence of cancers in this age group or under reporting of ADRs in the paediatric age group.

The most common anticancer drug causing ADR was imatinib followed by docetaxel. This is in contrast to the studies showing platinum and 5-Fluorouracil as the most common anticancer drugs associated with ADRs. ${ }^{12}$ This could be probably due to the availability of imatinib free of cost to the patients or due to the prevalence of cancer for which imatinib is a treatment option in our center. 


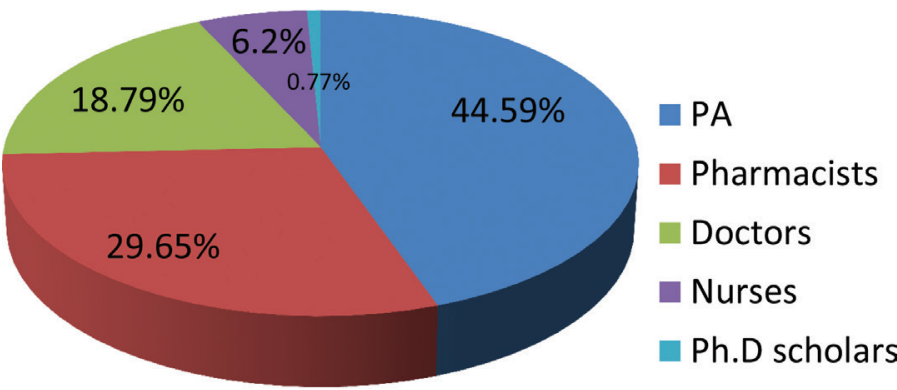

PA : Pharmacovigilance associate

Figure 4: ADR reported by healthcare professionals

Table 4: 10 most common anti-cancer drugs causing ADRs

\begin{tabular}{cccc}
\hline SI. No. & Drug & No. of ADRs & Percentage \\
\hline 1 & Imatinib & 308 & 13.94 \\
2 & Docetaxel & 211 & 9.55 \\
3 & Gemicitabine & 189 & 8.56 \\
4 & Paclitaxel & 163 & 7.38 \\
5 & Oxaliplatin & 146 & 6.61 \\
6 & Capecitabine & 116 & 5.25 \\
7 & 5-FU & 115 & 5.21 \\
8 & Vincristine & 68 & 3.08 \\
9 & 6-MP & 60 & 2.72 \\
10 & Gefitinib & 58 & 2.63 \\
\hline
\end{tabular}

The most common ADR due to anticancer drug in our setting was anemia followed by neuropathy. This is similar to the study conducted by Gunaseelan et al. in which anemia was the most common ADR. ${ }^{13}$ However study carried out by Mallik et al. reported neutropenia as the most common ADR on contrary to our finding of neutropenia as the third most commonly reported ADR ${ }^{14}$ According to a study by Sharma et al. most commonly occurring ADRs were infections (22.4\%), nausea/ vomiting $(21.6 \%)$, febrile neutropenia (13\%) and anaemia $(7.2 \%) .{ }^{10}$ The reason for these variations could be the non-reporting of mild ADRs like nausea and vomiting.

In our study, the most common organ system affected was blood followed by skin and appendages. This finding was related to the results of the study carried out by Mallik et al. ${ }^{14}$ Contrary to this study, Chopra et al. found that gastrointestinal tract is the most frequently involved organ system, followed by hematological system. ${ }^{12}$ However, gastrointestinal tract was the third most common organ system involved in our study. This may be due to the under reporting of nausea, vomiting and other mild ADRs related to gastrointestinal system in our Centre.

Most of the ADRs were reported by the technical associate followed by pharmacists and doctors. This is in contrast to the results of Kalaiselvan et al. that found doctors report majority of ADRs followed by pharmacists. ${ }^{15}$ The dissimilarity of our finding could be attributed to lack of time for reporting ADRs owing to high patient load in our setting and active involvement of our Pharmacovigilance associate who is working in department of Clinical Pharmacology on a regular basis under PvPI.

Causality assessment for most of the ADR was possible as per the WHOUMC causality assessment scale. This was similar to the study conducted by Chopra et al. ${ }^{11}$ On contrary, a study conducted by Saini et al. had most of the ADRs as probable 97 (64.67\%) followed by possible 53 (35.33\%). ${ }^{16}$ The major limitation of the study was inability to trace the patients and the reporting personnel for additional information owing to retrospective study design.

\section{CONCLUSION}

Cancer chemotherapeutic agents have a high propensity to cause ADRs owing to their action on rapidly dividing cells. Hence early detection of these ADRs may help in minimizing the harm either by modifying the dose or changing the concerned drug with a suitable alternative. This knowledge may help in preventing the occurrence of similar reactions in future. Accordingly, an efficient adverse drug reaction monitoring centre (AMC) and reporting system is mandatory in all hospitals to generate awareness among health care professionals. Measures to promote judicious use of drugs and reduce the incidence of adverse drug reactions (ADRs) will help in promoting quality of life apart from lessening economic burden of the patients.

\section{ACKNOWLEDGEMENT}

Authors are thankful to all heads of the departments, physicians and staff from where ADRs are collected for their support in reporting adverse drug reactions.

\section{CONFLICT OF INTEREST}

There are no conflicts of interest.

\section{ABBREVIATION USED}

ADR: Adverse drug reaction; AMC: Adverse drug reaction monitoring centre; CNS: Central Nervous system; HFS: Hand foot syndrome; GLOBOCAN: Global burden of cancer; PA: Pharmacovigilance associate; PNS: Peripheral Nervous System; PvPI: Pharmacovigilance Programme of India; RCC: Regional Cancer Centre; WHO: World Health Organization; UMC: Uppsala Monitoring Centre.

\section{REFERENCES}

1. WHO. The global burden of disease: 2004 update. Geneva: World Health Organization, [updated 2008; cited 2016 Oct 15].Available from: http://www.who.int/ healthinfo/global_burden_disease/GBD_report_2004update_full.pdf.

2. Ferlay J, Soerjomataram I, Ervik M, Dikshit R, Eser S, Mathers C, et al. GLOBOCAN 2012 v1.0, Cancer incidence and mortality worldwide: IARC Cancer Base No. 11 [Internet]. Lyon, France: international agency for research on cancer; 2013. Available from: http://globocan.iarc.fr. Last access on 15th Oct, 2016.

3. Chabner AC. General principles of cancer chemotherapy. In: Brunton LL, Chabner BA, Knollmann BC, editors. Goodman \& Gilman's the pharmacological basis of therapeutics. United States: McGraw-Hill; 2011. p1667-75

4. WHO-UMC.org. The use of the WHO-UMC system for standardised case causality assessment. [Internet] [Cited 2016 Oct 15]. Available from: http:// whoumc.org/Graphics/24734. pdf

5. Mrugank BP, Hareesha RP. Prospective observational, non-randomized, parallel sequence study for assessment of adverse drug reactions due to chemotherapeutic treatment in different types of cancer patients. Int J Pharm Sci Res. 2013;4(1):386-91

6. Jose J, Rao PG. Pattern of adverse drug reactions notified by spontaneous reporting in an Indian tertiary care teaching hospital. Pharmacol Res. 2006;54(3):226-33.

7. Aagaard L, Strandell J, Melskens L, Petersen PS, Hansen EH. Global patterns of adverse drug reactions over a decade. Drug Saf. 2012;35(12):1171-82.

8. Couffignal AL, Lapeyre-Mestre M, Bonhomme C, Bugat R, Montastruc JL. Adverse effects of anticancer drugs: apropos of a pharmacovigilance study at a specialized oncology institution. Therapie. 2000;55(5):635-41.

9. Supporting pharmacovigilance in developing countries. The systems perspective. [Internet]. [Cited 2016 Oct 16]. Available from: http://www.msh.org/projects/sps/SPS Documents/upload/SPS_PV_Paper.pdf

10. Sharma A, Kumari KM, Manohar HD, Bairy KL, ThomaS J. Pattern of adverse drug reactions due to cancer chemotherapy in a tertiary care hospital in South India. Perspect Clin Res. 2015;6(2):109-15. 
11. Pai SB, Kamath A, Saxena PPU, Sayeli $V$, Rakesh KB. A retrospective evaluation of adverse drug reactions due to cancer chemotherapy in a tertiary care hospital in South India. J Young Pharm, 2016;8(3):251-4

12. Chopra D, Rehan HS, Sharma V, Mishra R. Chemotherapy-induced adverse drug reactions in oncology patients: A prospective observational survey. Indian J Med Paediatr Oncol. 2016;37(1):42.

13. Gunaseelan V, Mandal SK, Prasad VN, Khumukcham R, Devi KK, et al. Adverse drug reactions to cancer chemotherapy in a regional cancer center in Northeast India. Int J Pharm Sci Res. 2014;5(8):3358-63
14. Mallik S, Palaian S, Ojha P, Mishra P. Pattern of adverse drug reactions due to cancer chemotherapy in a tertiary care teaching hospital in Nepal. Pak J Pharm Sci. 2007;20(3):214-18.

15. Kalaiselvan $V$, Prasad T, Bisht A, Singh S, Singh GN. Adverse drug reactions reporting culture in Pharmacovigilance Programme of India. Indian J Med Res. 2014;140(4):563-4

16. Saini VK, Sewal RK, Ahmad Y, Medhi B. Prospective observational study of adverse drug reactions of anticancer drugs used in cancer treatment in a tertiary care hospital. Indian J Pharm Sci. 2015;77(6):687-93.

Article History: Submission Date : 06-04-2017 ; Revised Date : 23-05-2017; Acceptance Date : 11-06-2017.

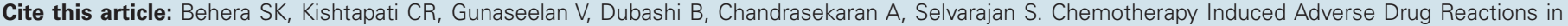
Cancer Patients in a Tertiary Care Hospital in South India. J Young Pharm. 2017;9(4):593-7. 